\section{Neonatal Sweet's syndrome associated with rectovestibular fistula with normal anus}

\author{
Jun Shinozuka, 1 Hideki Tomiyama,2 \\ Shin-ichiro Tanaka, 1 Junko Tahara, ${ }^{1}$ \\ Hitoshi Awaguni, ${ }^{1}$ Shigeru Makino, ${ }^{1}$ \\ Rikken Maruyama, ${ }^{1}$ Shinsaku Imashuku ${ }^{3}$ \\ 1Division of Pediatrics, ${ }^{2}$ Division of \\ Pediatric Surgery, ${ }^{3}$ Division of Laboratory \\ Medicine, Uji-Tokushukai Medical Center, \\ Uji, Kyoto, Japan
}

\section{Abstract}

Sweet's syndrome, characterized by fever and a painful erythematous rash with a dermal neutrophilic infiltrate, develops primarily due to paraneoplastic phenomena in adults. Sweet's syndrome is very rare in neonates. We report a Japanese female neonate (age $<2$ months), who developed Sweet's syndrome with episodes of perineal infection in association with congenital rectovestibular fistula with normal anus. Sweet's syndrome was diagnosed basing on clinical features and histopathology of biopsied skin tissues. Rectovestibular fistula was confirmed after the signs of inflammation subsided and the rash disappeared. In the literature, we found another case of neonatal Sweet's syndrome associated with rectovestibular fistula in a Japanese female neonate. The perineal region should be screened for anomalies following diagnosis of Sweet's syndrome in neonates.

\section{Introduction}

Acute febrile neutrophilic dermatosis, commonly known as Sweet's syndrome, is characterized by fever and painful skin lesions that appear on the face, neck, and trunk. Sweet's syndrome primarily occurs in adults and is relatively rare in children. ${ }^{1,2}$ According to a recent review article, fewer than 80 pediatric cases have been reported in literature, ${ }^{3}$ and reports of Sweet's syndrome in early infancy or neonatal periods are even rarer.4-6

Sweet's syndrome is commonly triggered by infections, drugs, collagen disease, or malignancies, ${ }^{1}$ although its causes tend to differ between adults and children. The syndrome is more commonly associated with infections in children, whereas it is most often associated with malignancies in adults. ${ }^{3}$ Generally, patients with Sweet's syndrome respond to treatment well and the outcome is favorable; however, underlying diseases may affect the final prognosis. ${ }^{1,2}$ We report here a Japanese neonate who was diagnosed with Sweet's syndrome triggered by a rare perineal infection associated with rectovestibular fistula without anal atresia.

\section{Case Report}

A 1.5-month-old female Japanese child was hospitalized due to fever and rash in 2014 . Initial presentation included papules resembling varicella on the scalp. Birth history was uneventful. Upon admission, the patient (4.9 $\mathrm{kg}$ in weight, $48 \mathrm{~cm}$ in height) was febrile $\left(37.7^{\circ} \mathrm{C}\right)$, and had a heart rate of 144 beats/min. She had signs of an upper respiratory infection, including cough and rhinorrhea. Papules were scattered on the face, neck, and trunk (Figure 1). On admission, she had leukocytosis associated with high C-reactive protein (CRP). Liver and renal functions were within normal limits (Table 1). We first suspected varicella lesions or pyoderma gangrenosum as infectious diseases and Langerhans cell histiocytosis as neoplastic disease; however, on the second day of hospitalization, at the dermatology clinic, Sweet's syndrome was highly suspected due to symptoms such as fever, neutrophilic leukocytosis, painfully looking erythematous plaques as well as nodules, and a skin biopsy was performed (Figure 2). Furthermore, to rule out neoplastic leukocytosis, we tested for myeloproliferative neoplasms (e.g., BCR/ABL and JAK2/V617F mutations), which were negative. No bone marrow aspiration was performed. Histopathology of skin biopsy was diagnosed compatible with Sweet syndrome. ${ }^{7}$ Varicella and Langerhans cell histiocytosis were ruled out. We started treatment with antibiotics (cefotaxime + ampicillin \pm VCM) and acyclovir, but four days after the diagnosis was obtained, prednisolone (initial dose $2 \mathrm{mg} / \mathrm{kg}$ followed by a taper; for 2 weeks) was introduced. As summarized in Table 1, serum CRP levels and leukocytosis improved in 2 weeks, in association with fading of the rash. On the other hand, platelet counts ( $>1.0$ million/ $/ \mathrm{L}$ ) and hepatic dysfunction appeared probably as adverse effects of treatment; however, laboratory data were normalized in 4 weeks. During the 4 weeks of hospitalization, her perineal problems were not evident and the patient was discharged with negative CRP and no rash. However, the patient was hospitalized again 2 weeks later with suspected vulvovaginal cellulitis. Her labia majora was red and swollen, and the perianal skin had sores. Cefazolin was prescribed. During this second hospitalization, the medical staff noticed vaginal fecal leakage. Rectovestibular fistula with normal anus was confirmed using a barium enema examination. Eventually, we diagnosed
Correspondence: Shinsaku Imashuku, Division of Laboratory Medicine, Uji-Tokushukai Medical Center, Uji, Kyoto 611-0042, Japan.

Tel.: +81.774.20.111 - Fax: +81.774.20.2336.

E-mail: shinim95@mbox.kyoto-inet.or.jp

Key words: Sweet's syndrome; neonate; rectovestibular fistula.

Acknowledgments: the authors would thank Dr. Kentaro Omoya who provided detailed information on the case reported in reference 7 .

Contributions: the authors contributed equally.

Conflict of interest: the authors declare no potential conflict of interest.

Received for publication: 9 February 2015.

Revision received: 25 May 2015.

Accepted for publication: 25 May 2015.

This work is licensed under a Creative Commons Attribution NonCommercial 3.0 License (CC BYNC 3.0).

(C) Copyright J. Shinozuka et al., 2015

Licensee PAGEPress, Italy

Pediatric Reports 2015; 7:5858

doi:10.4081/pr.2015.5858

this case as Sweet's syndrome based on the clinical, ${ }^{8}$ as well as histopathological, ${ }^{7}$ findings which occurred as a para-inflammatory phenomenon associated with perineal infection caused by the fistula. Written informed consent was obtained from the patient' parents for publication of this case report.

Only a similar case was found in the literature. ${ }^{9}$ A 1-month-old female Japanese neonate presented with fever and rash on the face that resembled varicella. She was febrile $\left(>38.0^{\circ} \mathrm{C}\right)$ with scattered erythematous papules over the face, trunk, and upper and lower extremities, with some showing a pustule-like appearance. Laboratory findings showed leukocytosis

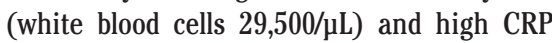
$(2.20 \mathrm{mg} / \mathrm{dL})$. Sweet's syndrome was diagnosed with a skin biopsy. She was treated with ampicillin and flomoxef sodium, along with dexamethasone (initial dose $2 \mathrm{mg} / \mathrm{kg}$, followed by a taper). Rash disappeared completely within 2 weeks. During the hospitalization, medical staff noticed vaginal fecal leakage. Further detailed examination confirmed that the patient had rectovestibular fistula with normal anus.

\section{Discussion and Conclusions}

In the diagnosis of Sweet syndrome, superficial bullous variant of pyoderma gangreno- 
sum, Behcet's disease and bacterial superinfection of varicella lesions must be ruled out. In particular, its diagnosis in neonates is difficult, because classic Sweet's syndrome occurs in middle-aged women, ${ }^{8}$ and reports of Sweet's syndrome in neonates or early infancy are rare. ${ }^{4,5,6,9} \mathrm{Mohr}$ et al. reported a 10-week-old male, ${ }^{4}$ and Sirbent $e t$ al. described a 7-monthold female. 5 Gray et al. reviewed 20 cases of neonatal Sweet's syndrome, including the case from Mohr et al., in the first 6 months of life based on the literature survey. Of these, six were associated with a virus, four with primary immunodeficiencies (PID), three with neonatal lupus syndrome (SLE), one with gastrointestinal involvement, one with human immunodeficiency virus (HIV), and five with genetic causes. ${ }^{6}$ Among the cases associated with infection, upper respiratory tract or gastrointestinal tract infections are most commonly noted, ${ }^{1}$ with no previously reported cases associated with rectovestibular fistula. Here, we reported a Japanese female neonate who developed Sweet's syndrome at $<2$ months of age associated with rectovestibular fistula. This case was similar to another Japanese neonate found in our literature survey. PID and SLE were unlikely in either of these cases. Human leukocyte antigen (HLA) typing was performed in the case reported by Omoya et al. ${ }^{9}$ because certain HLAs may be significantly associated with the development of Sweet's syndrome. Although the frequency of HLA-B54 is significantly higher in patients with the syndrome, 10 their patient did not have the HLAB54 type, ${ }^{9}$ and we did not determine HLA typing in our case. Sweet's syndrome in both of these Japanese neonates was triggered by perineal infection associated with rectovestibular fistula. Besides infection-associated Sweet syndrome, malignancy-associated, and druginduced variants of Sweet syndrome exist. It is recommended that the first treatment of choice for Sweet syndrome is systemic corticosteroids and this is generally effective.1,11 Both our case and the case reported by Omoya et al. were successfully treated with a combination of antibiotics and corticosteroids. For refractory cases mostly occurring in malignancy-associated or drug-induced Sweet syndrome, as alternative first-line therapies potassium iodide and colchicine are employed and as second-line treatments indomethacin, cyclosporine or dapsone could be administered. ${ }^{11}$ In these 2 cases, management of fistula was required after clinical features of Sweet syndrome have improved. In neonates with vaginal fecal leakage, labial abscess, and/or recurrent urinary tract infection with a normal anus, identifying the fistula located in the vestibule, vagina, or labia is essential.12-14 Diagnosis is often difficult, and rectovaginal and rectovestibular fistula must be differentially diagnosed. Many reports of congenital or acquired rectovestibular fistula without anal atresia are available from Asia.13,15 We believed that the rectovestibular fistula was congenital in our case because of the early onset shortly after birth. Surgical measures are currently under discussion as a radical treatment for rectovestibular fistula. Complete closure is essential because of the high risk of recurrent infection and Sweet's syndrome in the future. In summary, our case study indicates that although Sweet's syndrome is rare, caution must be exercised following its diagnosis to determine if any anomalies exist in the perineal region, particularly in neonates.

Table 1. Laboratory data after hospitalization.

\begin{tabular}{lcccc} 
& Day 1 & Day 6 & Day 15 & Day 26 \\
CRP $(\mathrm{mg} / \mathrm{dL})$ & 4.22 & 11.2 & 0.92 & 0.21 \\
WBC $(/ \mu \mathrm{L})$ & 24,500 & 19,800 & 18,000 & 10,700 \\
\hline Neutrophils, $\%$ & 42.0 & 80.0 & 58.0 & 58.0 \\
Hb $(\mathrm{g} / \mathrm{dL})$ & 11.5 & 10.0 & 10.5 & 10.6 \\
\hline Platelet count $(/ \mu \mathrm{L})$ & 662,000 & 656,000 & 1054,000 & 529,000 \\
AST $(\mathrm{IU} / \mathrm{L})$ & 20 & 19 & 156 & 31 \\
\hline ALT $(\mathrm{IU} / \mathrm{L})$ & 10 & 9 & 125 & 21 \\
LDH $(\mathrm{IU} / \mathrm{L})$ & 268 & 266 & 423 & 242 \\
\hline BUN(mg/dL) & 6.2 & 4.3 & 8.2 & 5.5 \\
Creatinine & 0.22 & 0.17 & 0.19 & 0.21 \\
\hline
\end{tabular}

CRP, C-reactive protein; AST, aspartate transaminase; ALT, alanine transaminase; LDH, lactate dehydrogenase; BUN, blood urea nitrogen.

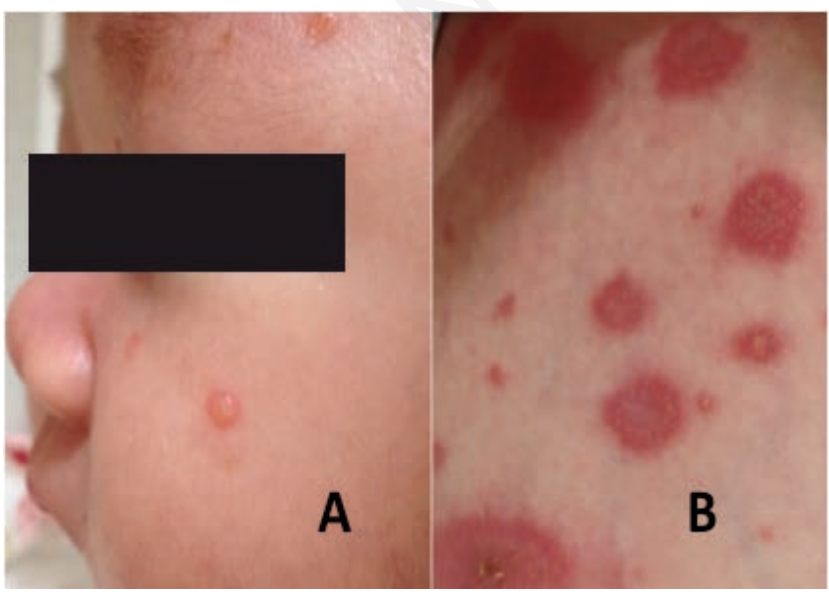

Figure 1. Photos of skin lesions. Photo shows a few varicella-like eruptions on the face (A) in association with numerous red papules of various sizes on the abdomen (B).

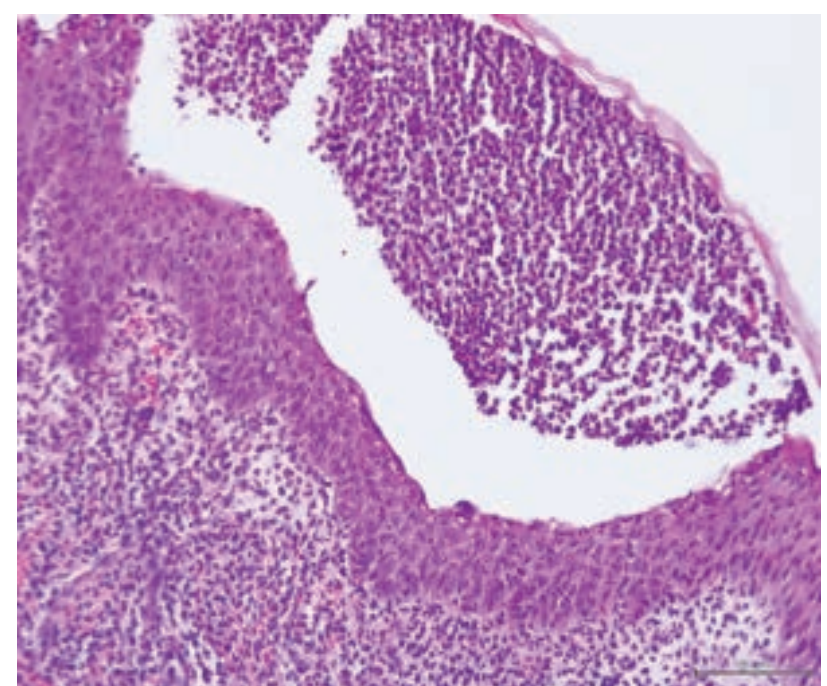

Figure 2. Biopsied specimen of skin shows a confluent neutrophilic infiltrate in the dermis and epidermis. 


\section{References}

1. Cohen PR. Sweet's syndrome--a comprehensive review of an acute febrile neutrophilic dermatosis. Orphanet J Rare Dis 2007;2:34.

2. Hospach T, von den Driesch P, Dannecker GE. Acute febrile neutrophilic dermatosis (Sweet's syndrome) in childhood and adolescence: two new patients and review of the literature on associated diseases. Eur J Pediatr 2009;168:1-9.

3. García-Romero MT, Ho N. Pediatric Sweet syndrome. A retrospective study. Int $\mathrm{J}$ Dermatol 2015;54:518-22.

4. Mohr MR, Torosky CM, Hood AF, et al. Sweet syndrome in infancy. Pediatr Dermatol 2010;27:208-9.

5. Sirvent N, Olivier V, Benet L, et al. [Sweet syndrome in an infant]. Arch Pediatr
2000;7:501-4. [Article in French].

6. Gray PE, Bock V, Ziegler DS, Wargon 0. Neonatal Sweet syndrome: a potential marker of serious systemic illness. Pediatrics 2012;129:e1353-9.

7. Jordaan HF. Acute febrile neutrophilic dermatosis. A histopathological study of 37 patients and a review of the literature. Am J Dermatopathol 1989;11:99-111.

8. von den Driesch P. Sweet's syndrome (acute febrile neutrophilic dermatosis) J Am Acad Dermatol 1994;31:535-56.

9. Omoya K, Naiki Y, Kato Z, et al. Sweet's syndrome in a neonate with non-B54 types of human leukocyte antigen. World $\mathrm{J}$ Pediatr 2012;8:181-4.

10. Mizoguchi M, Matsuki K, Mochizuki M, et al. Human leukocyte antigen in Sweet's syndrome and its relationship to Behçet's disease. Arch Dermatol 1988;124:1069-73.

11. Cohen PR. Neutrophilic dermatoses: a review of current treatment options. Am J Clin Dermatol 2009;10:301-12.

12. Petit T, Fouques Y, Viatounou S, et al. [Congenital rectovestibular fistula. An unusual diagnosis that should not be ignored]. Arch Pediatr 2002;9:595-7. [Article in French]

13. Li L, Zhang TC, Zhou CB, et al. Rectovestibular fistula with normal anus: a simple resection or an extensive perineal dissection? J Pediatr Surg 2010;45 :519-24.

14. Lawal TA, Chatoorgoon K, Bischoff A, et al. Management of $\mathrm{H}$-type rectovestibular and rectovaginal fistulas. J Pediatr Surg 2011;46:1226-30.

15. Tsugawa $C$, Nishijima E, Muraji T, et al. Surgical repair of rectovestibular fistula with normal anus. J Pediatr Surg 1999;34:1703-5 